12 Hall GL, Thompson BR, Stanojevic S, et al. The Global Lung Initiative 2012 reference values reflect contemporary Australasian spirometry. Respirology 2012; 17: 1150-1151.

13 França DC, Camargos PA, Jones MH, et al. Prediction equations for spirometry in four- to six-year-old children. J Pediatr 2016; 92: 400-408.

14 Bonner R, Lum S, Stocks J, et al. Applicability of the Global Lung Function spirometry equations in contemporary multiethnic children. Am J Respir Crit Care Med 2013; 188: 515-516.

15 Hüls A, Krämer U, Stolz S, et al. Applicability of the Global Lung Initiative 2012 reference values for spirometry for longitudinal data of elderly women. PLoS One 2016; 11: e0157569.

16 Arigliani M, Canciani MC, Mottini G, et al. Evaluation of the Global Lung Initiative 2012 reference values for spirometry in African children. Am J Respir Crit Care Med 2016; in press [DOI: 10.1164/rccm.201604-0693OC].

17 Kainu A, Timonen KL, Toikka J, et al. Reference values of spirometry for Finnish adults. Clin Physiol Funct Imaging 2016; 36: 346-358.

18 Backman H, Lindberg A, Sovijärvi A, et al. Evaluation of the global lung function initiative 2012 reference values for spirometry in a Swedish population sample. BMC Pulm Med 2015; 15: 26.

19 Quanjer PH, Kubota M, Kobayashi H, et al. Secular changes in relative leg length confound height-based spirometric reference values. Chest 2015; 147: 792-797.

20 Quanjer PH, Stocks J, Cole TJ, et al. Influence of secular trends and sample size on reference equations for lung function tests. Eur Respir J 2011; 37: 658-664.

21 Menezes AM, Wehrmeister FC, Hartwig FP, et al. African ancestry, lung function and the effect of genetics. Eur Respir J 2015; 45: 1582-1589.

22 Ben Saad H, El Attar MN, Hadj Mabrouk K, et al. The recent multi-ethnic global lung initiative 2012 (GLI2012) reference values don't reflect contemporary adult's North African spirometry. Respir Med 2013; 107: $2000-2008$.

23 Kumar R, Seibold MA, Aldrich MC, et al. Genetic ancestry in lung-function predictions. N Engl J Med 2010; 363: 321-330.

24 Pellegrino R, Viegi G, Brusasco V, et al. Interpretative strategies for lung function tests. Eur Respir J 2005; 26: 948-968.

25 Sobol BJ, Sobol PG. Per cent of predicted as the limit of normal in pulmonary function testing: a statistically valid approach. Thorax 1979; 34: 1-3.

26 Miller MR, Pincock AC. Predicted values: how should we use them? Thorax 1988; 43: $265-267$.

27 Soriano JB, Paton J, Martin Burrieza F, et al. The ERS Research Agency: the beginning. Eur Respir J 2016; 47: 1017-1023.

\title{
Viral mimic poly-(I:C) attenuates airway epithelial T-cell suppressive capacity: implications for asthma
}

To the Editor:

In allergen-sensitised asthmatic individuals, allergen-specific type-2 T-helper cells proliferate and secrete type-2 cytokines (e.g. interleukin (IL)-4, -5 and -13), driving the airway inflammatory response that gives rise to the clinical symptoms of asthma. Both early-life sensitisation to aeroallergens and lower respiratory viral infections are important environmental risk factors for developing asthma. Additionally, respiratory viral infections are the most common trigger for asthma exacerbations. Of interest, many asthma susceptibility genes are expressed in the airway epithelium [1], which forms the first continuous line of defence against inhaled environmental insults, including viruses and aeroallergens. Impaired immune regulation and failure to maintain tolerance to allergens is thought to contribute to allergic sensitisation. Asthma epithelium may be deficient in its innate immune defence against viral infections, resulting in increased viral replication upon rhinovirus infection compared to nonasthma-derived epithelial cultures [2]. Furthermore, there is evidence for loss of the mucosal immune barrier in asthma, with disruption of epithelial integrity $[1,3]$. This may lead not only to increased permeability, but also to the release of pro-inflammatory mediators, specifically of cytokines that drive type-2 responses $[3,4]$. We recently observed that the ability of allergens to disrupt epithelial barrier function is related to the development of type-2-mediated inflammation in asthma [5, 6]. Furthermore, we demonstrated that healthy murine lung epithelium is a potent inhibitor of T-cell proliferation and that this inhibition is lost upon viral infection [7]. It is unknown if this immune regulatory effect is displayed by human epithelium and is dysregulated in asthma. We hypothesise that changes in this regulatory effect translate into aberrant regulation of T-cell responses in asthma. We studied the epithelial regulation of T-cell proliferation and cytokine responses upon epithelial stimulation with a viral mimic, using co-culture of human T-cells and primary bronchial epithelial cells (PBECs) from healthy controls and asthma patients. 
Normal PBECs obtained from Lonza (Walkersville, MD, USA) were used, except for the comparison between healthy and asthmatic epithelium, when PBECs derived by bronchial brushings from five healthy individuals and five patients with mild-moderate asthma, all nonsmokers, were used (see figure le for further characteristics). The study was approved by the medical ethics committee of the University Medical Center Groningen (Groningen, the Netherlands). All subjects gave their written informed consent. PBECs were cultured in hormonally supplemented bronchial epithelium growth medium (BEGM; Lonza) as described previously [8-10]. PBECs were seeded in 12-well plates, grown to 90\% confluence, placed in BEGM/1\% fetal calf serum (FCS) overnight and pretreated with/without $12.5 \mu \mathrm{g} \cdot \mathrm{mL}^{-1}$ poly-(I:C) for $8 \mathrm{~h}$ and washed before placing in co-culture with T-cells. $\mathrm{CD}^{+} \mathrm{T}$-cells were isolated from $10 \mathrm{~mL}$ peripheral blood of healthy nonallergic nonsmoking volunteers using Ficoll-Hypaque (Lymphoprep; Nycomed, Oslo, Norway) density-gradient centrifugation followed by magnetic-activated cells sorting (MACS) using $\mathrm{CD}^{+}{ }^{\mathrm{T}}$-cell Isolation Kit II (Miltenyi Biotec, San Diego, CA, USA). T-cells were seeded in duplicates at a concentration of $1.25 \times 10^{5}$ cells $\cdot \mathrm{mL}^{-1}$ in 12-well plates with/without PBECs (2:1 PBECs:T-cells) or in the upper well of a transwell system $(0.4 \mu \mathrm{M}$ pores, Corning Costar, Corning, NY, USA) placed above PBECs. T-cells were stimulated for $96 \mathrm{~h}$ in the presence/absence of PBECs in BEGM/1\% FCS or in conditioned medium from $24 \mathrm{~h}$ PBEC culture. T-cell proliferation was induced by $\alpha$-CD3/ $\alpha$-CD28 immobilised to beads (Dynabeads; Invitrogen, Carlsbad, CA, USA) and analysed by labelling with $10 \mu \mathrm{M}$ carboxyfluoroscein succinimidyl ester (CFSE; Life Technologies, Grand Island, NY, USA) just prior to stimulation. CFSE dilution measurements were performed using flow cytometry (Calibur, BD, Breda, the Netherlands) in viable $\mathrm{CD}^{+}$/ 7-amino-actinomycin-D ${ }^{\text {negative }}$ T-cells. The division index was calculated at $(100-\mathrm{Y}) / \mathrm{Y}$, where $\mathrm{Y}(\%)=\mathrm{x}_{0}+$ $\mathrm{x}_{1} / 2+\mathrm{x}_{2} / 4+\mathrm{x}_{3} / 8+\mathrm{x}_{4} / 16, \mathrm{x}_{0}=\%$ of T-cells that have not divided and $\mathrm{x}_{1-4}=\mathrm{T}$-cells within progressive CFSE division gates. Levels of interferon (IFN)- $\gamma$, IL-4, IL-5, IL-10 and IL-13 were analysed in cell-free supernatants using a multiplex ELISA kit (Millipore, Billerica, MD, USA) and Luminex technology (Luminex Corporation, Austin, TX, USA).

We first studied the regulatory effects of healthy human PBECs on T-cell proliferative responses and observed an almost complete prevention of $\alpha$-CD3/ $\alpha$-CD28-induced T-cell proliferation, with suppression of all T-cells (figure 1a and b), without significant effects on T-cell viability (not shown). We previously observed in mice that T-cell proliferation was equally well suppressed by lung epithelial cells, whether they were cultured submerged or at the air-liquid interface (data not shown). Here, we show that the suppressive effect was still present when PBECs and T-cells were separated in a transwell system, suggesting that the effect does not require direct cell-cell contact (figure 1b). In addition, the suppressive effect could be transferred by conditioned medium derived from 24-h culture of the epithelial cells (figure 1c), indicating the involvement of one or several soluble mediators. Assessing cytokine production, there was no significant effect on the type-1 cytokine IFN- $\gamma$, while healthy PBECs strongly inhibited the $\alpha$-CD3/ $\alpha$-CD28-induced secretion of the type- 2 cytokines IL-4, IL-5, IL-10 and IL-13 (figure 1d). PBECs cultured alone did not secrete detectable levels of any of these cytokines.

To study whether airway epithelium in asthma is deficient in its immunosuppressive capacity, we compared the effect of PBECs from asthma patients and healthy controls (figure 1e). Both asthma-derived and control-derived PBECs formed confluent cell monolayers, without morphological differences as observed by microscopy, and both markedly inhibited T-cell proliferation (figure 1f). However, asthma-derived PBECs were significantly less potent in doing so (figure 1f). Furthermore, PBECs from both asthmatics and healthy controls had a similar capacity to inhibit type-2 cytokine production, as shown for IL-13 (figure 1g), without significant differences between the subject groups.

We previously showed that the regulatory effect of healthy murine epithelial cells was lost upon viral infection [7]. Respiratory RNA viruses act on Toll-like receptor (TLR)3, potentially mediating airway inflammation in virus-induced asthma exacerbations [11, 12]. Therefore, we used the TLR3 agonist poly-(I:C) as a viral mimic. PBECs from controls and asthmatics were exposed to poly-(I:C) and then washed, leaving the cells viable and fully confluent, before T-cells were added. Pretreatment with poly-(I:C) strongly reduced the suppressive effect of both control and asthma-derived PBECs on T-cell proliferation (figure $1 \mathrm{~h}$ and i) and attenuated the inhibitory effect of control PBECs on type-2 cytokine secretion, as shown for IL-13 (figure $1 \mathrm{j}$ ).

Together, our data suggest that asthma and viral infection compromise the immunosuppressive capacity of airway epithelium, which may be most impaired during virus-induced exacerbations of asthma, resulting in severe inflammation and a loss of asthma control. Such a major compromise of epithelial immune suppressive capacity was not found and not expected in the epithelium from stable asthma patients studied here. Viral infection of murine pulmonary epithelial cells strongly reduces their T-cell suppressive capacity [7] and our current data indicate that viral infection of human airway epithelial cells will have a similar effect. Even without using a live virus, the epithelial immunosuppressive effect on T-cells was strongly attenuated upon exposure to the viral mimic and TLR3 agonist poly-(I:C). We 
a)

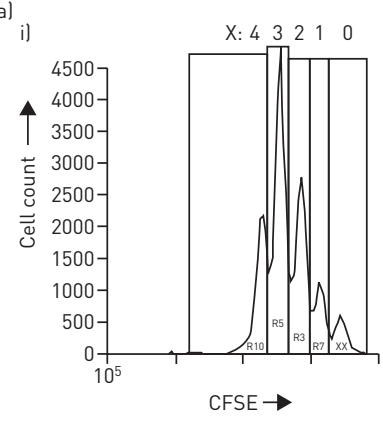

ii)

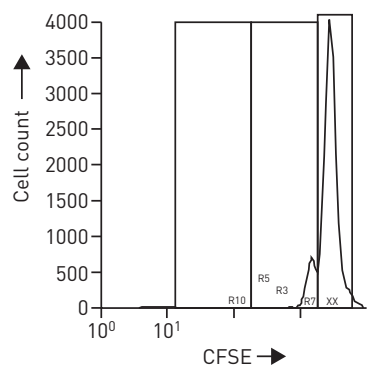

b)

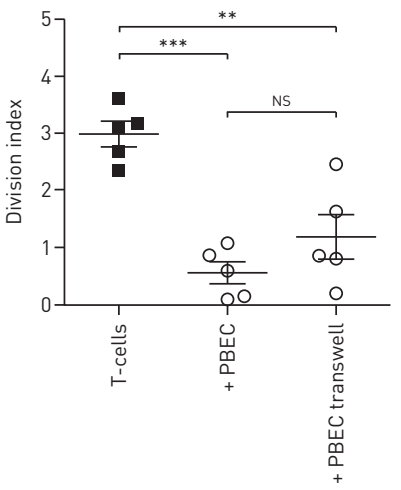

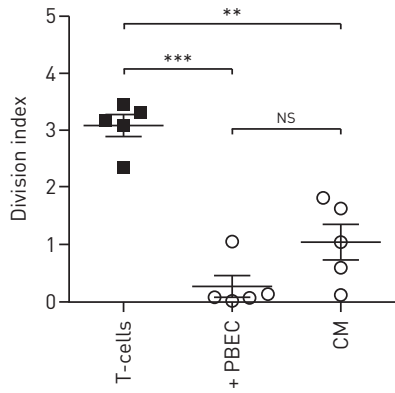

d)

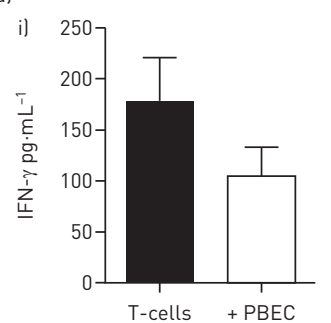

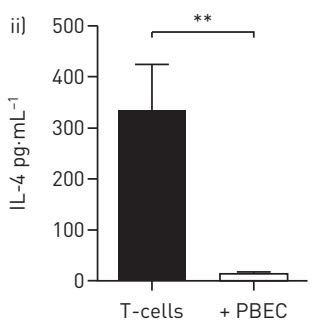
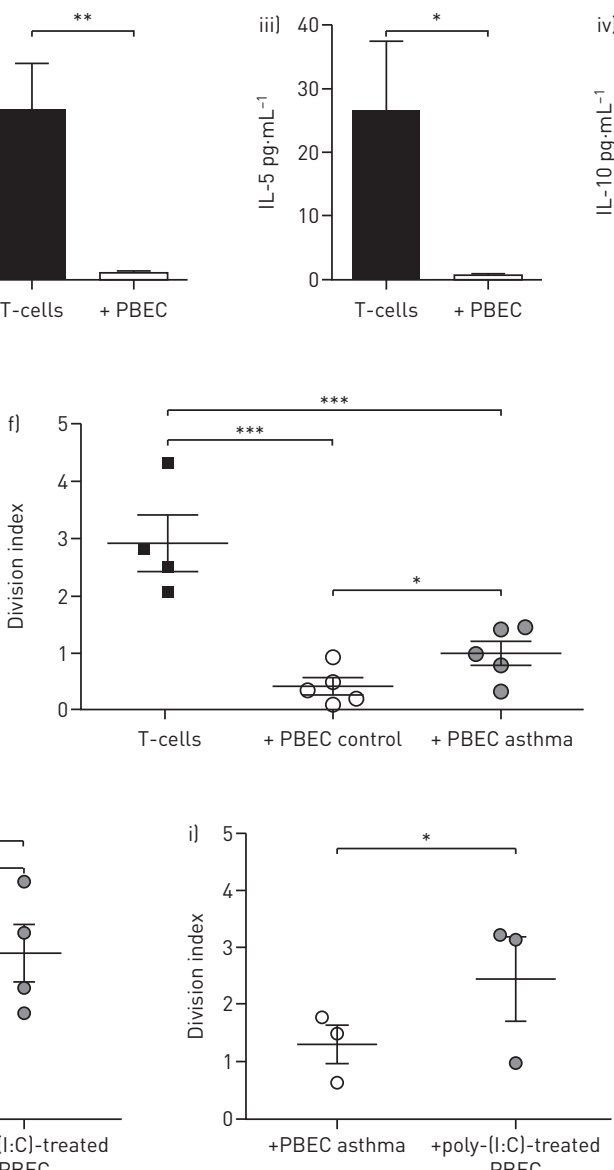

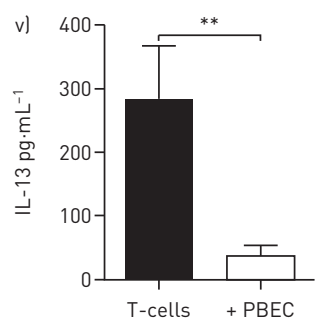

e)

\begin{tabular}{|c|c|c|}
\hline Subject & \multicolumn{1}{c}{$\begin{array}{c}\text { Asthma } \\
\mathrm{n}=5\end{array}$} & $\begin{array}{c}\text { Control } \\
\mathrm{n}=5\end{array}$ \\
\hline Age years & $50(38-58)$ & $48(21-55)$ \\
\hline Sex M/F & $1 / 4$ & $1 / 4$ \\
\hline FEV $_{1} \%$ pred & $89(83-100)$ & $111(103-114)$ \\
\hline
\end{tabular}
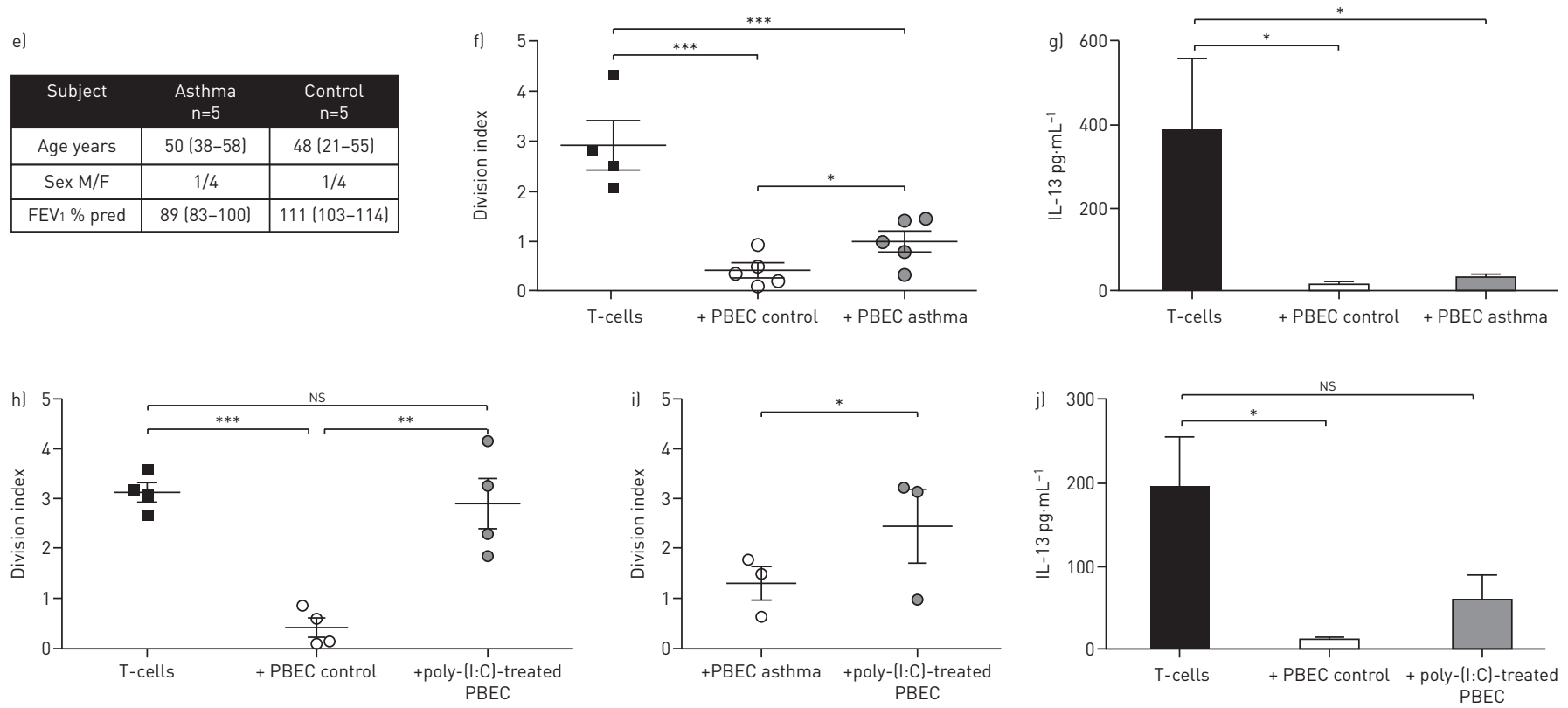

FIGURE 1 Primary bronchial epithelial cells (PBECs) inhibit $\alpha$-CD3/ $\alpha$-CD28-induced T-cell proliferation and associated type-2 cytokine production, an effect that is attenuated by viral stimulation and in asthma. a) Representative carboxyfluoroscein succinimidyl ester (CFSE) dilution measurement in i) T-cells alone and ii) T-cells + PBECs. b) Proliferation of T-cells cultured in direct contact with PBECs (Lonza, Walkersville, MD, USA) compared to T-cells and PBECs separated in a transwell system ( $n=5)$. c) Proliferation of T-cells cultured in conditioned medium (CM) of 24-h PBEC (Lonza) cultures ( $n=5)$. d) i) interferon (IFN)- $\gamma$, ii) interleukin (IL)-4, iii) IL-5, iv) IL-10 and v) IL-13 levels measured in cell-free supernatants using multiplex ELISA after T-cell stimulation with $\alpha-C D 3 / \alpha-C D 28$-coupled beads for 4 days in the absence/presence of PBECs (Lonza) ( $n=9-10)$. e) Characteristics of the subjects from whom bronchial brushings were taken. Stable mild-moderate asthma patients were included based on the presence of allergy (assessed by skin test or Phadiatop (Phadia, Uppsala, Sweden)) and bronchial hyperresponsiveness lassessed by $\mathrm{PC}_{20}$ (provocative concentration causing a $20 \%$ fall in forced expiratory volume in $1 \mathrm{~s}\left(\mathrm{FEV} 1\right.$ )) of $A M P<16 \mathrm{mg} \cdot \mathrm{mL}^{-1}, \mathrm{methacholine}$ $<8 \mathrm{mg} \cdot \mathrm{mL}^{-1}$ or histamine $<8 \mathrm{mg} \cdot \mathrm{mL}^{-1}$ ), and the absence of other lung diseases and of any corticosteroid, long-acting $\beta$-agonist and long-acting anticholinergic use for $\geqslant 4$ weeks preceding the study. Data are presented as median (range) or $\mathrm{n}$ (\%). f) Proliferation of T-cells cultured with/ without PBECs from controls or asthma patients. g) IL-13 levels in cell-free supernatants of the T-cells co-cultured with/without PBECs from controls or asthma patients $(n=5)$. h) Proliferation of T-cells cultured alone, with PBECs (Lonza), or with PBECs (Lonza) that were pretreated with $12.5 \mu \mathrm{g} \cdot \mathrm{mL}^{-1}$ poly-(I:C) $(\mathrm{n}=5)$. i) Proliferation of T-cells cultured with PBECs from asthma patients that were pretreated with/without $12.5 \mu \mathrm{g} \cdot \mathrm{mL}^{-1}$ poly-(I:C) (n=3). j) IL-13 levels in cell-free supernatants of the co-cultures described in h). Data are presented as mean \pm SEM. M: male; F: female. *: $p<0.05 ;{ }^{* *}: p<0.01 ;{ }^{* * *}: p<0.001$ as analysed by one-way ANOVA with Bonferroni's multiple comparison test in all graphs, except for panels d) and i), where unpaired and paired t-tests were used, respectively. 
speculate that such inhibition of epithelial immune regulation could enhance type- 2 cytokine secretion during viral infection in early life, an important risk factor for asthma development, and during virus-induced asthma exacerbations. Indeed, viral infection is accompanied by an increase in type-2 cytokine secretion in mouse models [13] and in asthmatic airways, where type-2 cytokine levels relate to exacerbation severity [14].

In conclusion, we show that human bronchial epithelium exerts potent inhibitory effects on T-cell proliferation and type- 2 cytokine secretion. These effects are attenuated following exposure to a viral mimic, and asthma epithelium displays reduced inhibition of T-cell proliferation. Identification of the responsible mechanisms and mediator(s) involved in epithelial immune regulation may provide new targets for novel disease modifying therapeutic and preventive strategies in asthma.

@ERSpublications

Airway epithelial regulation of $\mathrm{T}$-cell activity may be impaired during virus-induced exacerbations in asthma http://ow.ly/b9KB303KVul

Jürgen Schwarze ${ }^{1}$, Paul M. Fitch ${ }^{1}$, Janneke Heimweg ${ }^{2}$, Claire Errington ${ }^{1}$, Reina Matsuda ${ }^{1}$, Harold G. de Bruin ${ }^{2}$, Maarten van den Berge ${ }^{3,4}$, Antoon J.M. van Oosterhout ${ }^{4}$ and Irene H. Heijink ${ }^{2,3,4}$

${ }^{1}$ University of Edinburgh, MRC Centre for Inflammation Research, Queen's Medical Research Institute, Edinburgh, UK.

${ }^{2}$ University of Groningen, University Medical Center Groningen, Department of Pathology and Medical Biology, Experimental Pulmonology and Inflammation Research, Groningen, The Netherlands. ${ }^{3}$ University of Groningen, University Medical Center Groningen, Department of Pulmonology, Groningen, The Netherlands. ${ }^{4}$ University of Groningen, University Medical Center Groningen, GRIAC Research Institute, Groningen, The Netherlands.

Correspondence: Irene H. Heijink, University Medical Center Groningen, Hanzeplein 1, 9713 GZ, Groningen, The Netherlands. E-mail: h.i.heijink@umcg.nl

Received: Oct 292015 | Accepted after revision: Aug 222016 | First published online: Oct 062016

Conflict of interest: Disclosures can be found alongside this article at erj.ersjournals.com

\section{References}

1 Nawijn MC, Hackett TL, Postma DS, et al. E-cadherin: gatekeeper of airway mucosa and allergic sensitization. Trends Immunol 2011; 32: 248-255.

2 Wark PA, Johnston SL, Bucchieri F, et al. Asthmatic bronchial epithelial cells have a deficient innate immune response to infection with rhinovirus. J Exp Med 2005; 201: 937-947.

3 Hackett TL, Singhera GK, Shaheen F, et al. Intrinsic phenotypic differences of asthmatic epithelium and its inflammatory responses to respiratory syncytial virus and air pollution. Am J Respir Cell Mol Biol 2011; 45: $1090-1100$.

4 Heijink IH, Kies PM, Kauffman HF, et al. Down-regulation of E-cadherin in human bronchial epithelial cells leads to epidermal growth factor receptor-dependent Th2 cell-promoting activity. J Immunol 2007; 178: 7678-7685.

5 Post S, Nawijn MC, Hackett TL, et al. The composition of house dust mite is critical for mucosal barrier dysfunction and allergic sensitisation. Thorax 2012; 67: 488-495.

6 Post S, Nawijn MC, Jonker MR, et al. House dust mite-induced calcium signaling instigates epithelial barrier dysfunction and CCL20 production. Allergy 2013; 68: 1117-1125.

7 Wang H, Su Z, Schwarze J. Healthy but not RSV-infected lung epithelial cells profoundly inhibit T cell activation. Thorax 2009; 64: 283-290.

8 Heijink IH, Marcel KP, van Oosterhout AJ, et al. Der p, IL-4, and TGF- $\beta$ cooperatively induce EGFR-dependent TARC expression in airway epithelium. Am J Respir Cell Mol Biol 2007; 36: 351-359.

9 Borger P, Kauffman HF, Scholma J, et al. Human allogeneic CD2+ lymphocytes activate airway-derived epithelial cells to produce interleukin-6 and interleukin-8. Possible role for the epithelium in chronic allograft rejection. J Heart Lung Transplant 2002; 21: 567-575.

10 Lordan JL, Bucchieri F, Richter A, et al. Cooperative effects of Th2 cytokines and allergen on normal and asthmatic bronchial epithelial cells. J Immunol 2002; 169: 407-414.

11 Zhu L, Lee PK, Lee WM, et al. Rhinovirus-induced major airway mucin production involves a novel TLR3EGFR-dependent pathway. Am J Respir Cell Mol Biol 2009; 40: 610-619.

12 Wood LG, Simpson JL, Wark PA, et al. Characterization of innate immune signalling receptors in virus-induced acute asthma. Clin Exp Allergy 2011; 41: 640-648.

13 Openshaw PJ. Immunity and immunopathology to respiratory syncytial virus. The mouse model. Am J Respir Crit Care Med 1995; 152: S59-S62.

14 Jackson DJ, Makrinioti H, Rana BM, et al. IL-33-dependent type 2 inflammation during rhinovirus-induced asthma exacerbations in vivo. Am J Respir Crit Care Med 2014; 190: 1373-1382. 